\title{
Effects of biofeedback on obstructive defecation - reconditioning of the defecation reflex?
}

\author{
M Papachrysostomou, A N Smith
}

\begin{abstract}
Twenty two patients with obstructive defecation were recruited for relaxation training by domiciliary self regulatory biofeedback. Each patient served as his or her own control for anorectal and proctographic assessments. Biofeedback training improved the obstructive symptoms of the patients and showed significant change in various parameters related to the obstructive defecation syndrome. As examined by isotope dynamic proctography: the defecation rate (\% of evacuation/ defecation time) was significantly increased $(p<0.05)$, the anorectal angles at rest and during attempted defecation were made more obtuse $(p<0.05)$, and the pelvic floor movements were made more dynamic on voluntary contraction of the anal sphincter $(p<0.03)$. The external anal sphincter electromyographic voltage recorded during defecation was significantly reduced $(p<0.0005)$ as was the surface anal plug electromyographic electrode voltage $(\mathbf{p}<0.0001)$, which was associated with a greatly reduced anismus index $(\mathbf{p}<0.0001)$. The rectal sensation was improved $(p<0.05)$, cocomitantly. Biofeedback thus improves the defecation act in patients suffering from inappropriate contraction of the pelvic floor and sphincter musculature. Furthermore, this study has shown that biofeedback objectively influences the defecation reflex leading to an improved quality of higher control of bowel function.
\end{abstract}

(Gut 1994; 35: 252-256)

The applicability of instrumental learning to the relief of gastrointestinal disorders is now almost unquestionable. Biofeedback has been used successfully to achieve strengthening of the contractions of the lower oesophageal sphincter in patients with reflux oesophagitis through instrumental learning, which was promoted by displaying lower oesophageal sphincter pressure. It has been used similarly in patients with faecal incontinence, aiming at strengthening the contraction of the anal sphincters. ${ }^{1-5}$

The study of the psychological as well as physiological characteristics of patients with severe idiopathic constipation ${ }^{6}$ encouraged the application of the biofeedback self regulation technique to constipation. The relief of functional constipation, or dyschezia, has become an obvious goal. Bleijenberg and Kuijpers ${ }^{7}$ have described a method of treatment of the spastic pelvic floor syndrome with biofeedback, after the patients have been in hospital for two weeks. This treatment though successful has caused concern to physicians and patients because of the comparatively long stay in hospital. The opportunity arose to apply this method to the treatment of the spastic pelvic floor syndrome, through the use of a small portable device suitable for domiciliary treatment. ${ }^{8}$ Since then, biofeedback treatment in obstructive defecation has become acknowledged ${ }^{9}$ as the foremost treatment for this condition with effects lasting for at least six months after treatment. ${ }^{8}$

Although the subjective effects were, however, well appreciated by clinicians and patients, ${ }^{10}$ there was no objective evidence as to how and what is the influence of the biofeedback on the anorectal function. Our study investigates the objective effects of biofeedback treatment on anorectal function in patients with obstructive defecation. It examines aspects of the defecation reflex in disturbed defecation with anorectal manometry, electrophysiology, and proctography. The study also aims at an exploration of the mechanisms of the biofeedback influences in the neural control of defecation.

\section{Patients and methods}

\section{SUBJECTS}

Twenty two patients were recruited, median age 42 years (age range: 32 to 50 ). Seventeen of them were females $(77 \%)$ and five were males $(23 \%)$. Seven of the females were nulliparous $(41 \%)$ and six were multiparous (with three children or more). Ethical permission for this work was obtained from the ethical committee of the Lothian Health Board, Edinburgh. Informed consent was also obtained from all patients.

The patients suffered from constipation for three to 25 years and complained of prolonged straining at stool. They could not perform rectal balloon expulsion and had inappropriate contraction of the external anal sphincter on straining as evidenced by electromyographic studies. Transit studies performed showed that radiopaque pellets retained were less than 10 , in a period of three to eight days after ingestion, thus excluding slow transit constipation. Conversely no markers were passed within the first 72 hours and the pellets were retained in the rectosigmoid region. All had a barium enema excluding organic disease and a normal rectoanal inhibitory reflex. Although all patients had detectable inappropriate contraction of the pelvic floor muscles on straining their symptomatology varied as follows: the frequency of defecation ranged from thrice daily to once a week, but with 16 patients complaining of incomplete emptying of the bowels $(73 \%) ; 15$ patients complained of perineal pain and discomfort of defecation (68\%), 14 complained of abdominal pain and distension (64\%), nine patients could not evacuate without the use of 
laxatives or enemas, or both $(41 \%)$, seven had a feeling of obstruction on defecation $(32 \%)$, and two of them could not begin defecation without digital evacuation.

\section{METHODS}

\section{Anorectal manometry and electrophysiology}

Conventional anorectal manometry using a $4 \mathrm{~mm}$ microballoon connected to an external transducer permitted measurements of the functional anal canal length, the maximum resting pressure, and the anal canal pressure increment on voluntary and cough reflex anal sphincter contraction. The rectosphincteric inhibitory reflex was performed in all patients to exclude aganglionosis as the cause of constipation. Proctometrograms were performed eliciting the volumes of the rectal sensory threshold, the maximum tolerable rectal capacity, and the rectal compliance. Electrophysiological tests included the latency of the pudendoanal reflex and integrated electromyography of the external anal sphincter via a surface electromyographic anal plug electrode. The anismus index was derived as the relation of the electromyographic voltage of the external anal sphincter on straining to the electromyographic voltage of the external anal sphincter on squeezing in the formula:

$$
\text { Anismus index }=\frac{\text { Increment of electromyographic voltage on straining }}{\text { Increment of electromyographic voltage on 'squeezing' }} \times 100
$$

\section{Isotope proctography}

Isotope dynamic proctography combined with simultaneous recording of external anal sphincter electromyography, with the use of wire electrodes, and intrarectal telemetry were performed in all patients as described in an earlier study. " The parameters recorded were the percentage of the activity evacuated (\%EVAC), the defecation time (seconds), and the defecation rate (\%EVAC/second); anorectal angle at rest, on maximal anal sphincter contraction during voluntary 'squeezing', on straining and during evacuation; and the pelvic floor movements on voluntary contraction of the anal sphincter, on straining and during evacuation.

\section{Rectal balloon expulsion test}

Before isotope proctography rectal balloon expulsion tests were performed in all patients. The proctometrogram balloon was inserted in the rectum and filled with saline up to a level of sensory awareness (approximately $140 \mathrm{ml}$ ). The patient was then asked to evacuate this balloon. (An unaided expulsion of the rectal balloon would have excluded at this stage any obstructive phenomena.)

\section{Biofeedback training}

The patients, after a preliminary evaluation of their symptoms and results of the investigations, and after consultation with the referring consultant were recruited to the biofeedback study. This entailed the attendance of the patient to the hospital on an outpatient basis on at least three occasions. During these visits theoretical and practical instructions were given of how to operate the biofeedback Myotron device.$^{8}$ This was combined with rectal balloon expulsion exercises that aimed at improving rectal sensory awareness and stimulating anal sensation of the inappropriate contraction of the pelvic floor muscles obstructing the expulsion of the filled balloon. When the patient and investigator were satisfied about the competence of the patient in performing the rectal balloon expulsion exercises and the ability to operate the Myotron device, the patient was given the device for a domiciliary course of minimum four weeks duration.

\section{STATISTICAL ANALYSIS}

The statistical analysis of the results used the median values and their $95 \%$ confidence intervals (CI) and the non-parametric sign test for comparison of paired findings.

\section{Results}

\section{ASSESSMENT BEFORE BIOFEEDBACK}

\section{Anorectal manometry and electrophysiology}

The Table shows the results of the anorectal manometry and proctometrogram studies and also shows the results of the electrophysiological tests, which showed that the pudendoanal reflex latency was delayed and gives the integrated electromyographic voltage of the external anal spincter elicited via the surface anal plug electromyographic electrode at rest and on straining. Obstructive defecation was implemented via a high anismus index.

\section{Isotope proctography}

The Table shows the results of the isotope dynamic proctography depicting \%EVAC, defecation time and rate, anorectal angles at rest, on 'squeezing', straining, and during evacuation, as well as pelvic floor descent on straining and evacuation; the isotope dynamic proctographys at rest, on straining and on evacuation are also given. The electromyography of the external anal sphincter performed simultaneously during isotope proctography with wire electrodes depicted the electromyographic voltage at rest, on squeezing, on straining and on evacuation.

\section{Rectal balloon expulsion test}

All the patients could not expel the rectal balloon unaided in the first instance, but achieved successful expulsions by the end of the hospital training programme before the domiciliary biofeedback. The rectal balloon expulsion exercises ranged from 2 to 5 sessions, for each patient; each session lasting $1 \cdot 5-2 \cdot 0$ hours duration.

\section{ASSESSMENT AFTER BIOFEEDBACK}

The patients completed a domiciliary course of biofeedback with a median duration of 36 days 
The effect of biofeedback training

\begin{tabular}{|c|c|c|c|}
\hline & $\begin{array}{l}\text { Before biofeedback } \\
(\text { mean }(95 \% \text { CIs }))\end{array}$ & $\begin{array}{l}\text { After biofeedback } \\
(\text { mean }(95 \% \text { CIs }))\end{array}$ & $p$ \\
\hline \multicolumn{4}{|l|}{ Anorectal manometry } \\
\hline $\operatorname{MRP}\left(\mathrm{cmH}_{2} \mathrm{O}\right)$ & $120(110$ to 140$)$ & $120(92$ to 128$)$ & \\
\hline $\mathrm{SQP}\left(\mathrm{cmH}_{2} \mathrm{O}\right)$ & $80(50$ to 130$)$ & $90(72$ to 108$)$ & \\
\hline SEN $(\mathrm{ml})$ & $138(110$ to 180$)$ & $100(90$ to 170$)$ & $<0.05$ \\
\hline $\mathrm{CAP}(\mathrm{ml})$ & $425(310$ to 496$)$ & $415(355$ to 481$)$ & \\
\hline $\mathrm{COM}\left(\mathrm{ml} / \mathrm{cmH}_{2} \mathrm{O}\right)$ & $6 \cdot 4(4 \cdot 2$ to $7 \cdot 3)$ & $6.0(5.0$ to 8.0$)$ & \\
\hline \multicolumn{4}{|l|}{ Electrophysiology } \\
\hline AI (\%) & $67(50$ to 80$)$ & $0(-2$ to 0$)$ & $<0.0001$ \\
\hline PARL (ms) & $48(42$ to 52$)$ & 40 (37 to 48$)$ & \\
\hline EASEMG $($ rest $\mu \mathrm{V})$ & $20(10$ to 40$)$ & $23(10$ to 42$)$ & \\
\hline EASEMG (straining $\mu \mathrm{V}$ ) & $50(25$ to 100$)$ & $25(10$ to 43$)$ & $<0.02$ \\
\hline EASEMG (evacuation $\mu \mathrm{V}$ ) & $100(53$ to 100$)$ & $15(7$ to 43$)$ & $<0.001$ \\
\hline \multicolumn{4}{|l|}{ Isotope proctography } \\
\hline $\operatorname{EVAC}(\%)$ & $56(46$ to 72$)$ & $61(42$ to 71$)$ & \\
\hline DTIME (s) & $112(52$ to 167$)$ & 64 (40 to 117$)$ & \\
\hline DRATE $(\% / s)$ & $0.5(0.2$ to 1.0$)$ & $0.8(0.5$ to 1.5$)$ & $<0.05$ \\
\hline ARA rest & $103^{\circ}\left(92^{\circ}\right.$ to $\left.106^{\circ}\right)$ & $110^{\circ}\left(104^{\circ}\right.$ to $\left.114^{\circ}\right)$ & $<0.05$ \\
\hline ARA straining & $112^{\circ}\left(96^{\circ}\right.$ to $\left.117^{\circ}\right)$ & $119^{\circ}\left(108^{\circ}\right.$ to $\left.131^{\circ}\right)$ & $<0.05$ \\
\hline ARA evacuation & $127^{\circ}\left(20^{\circ}\right.$ to $\left.133^{\circ}\right)$ & $137^{\circ}\left(129^{\circ}\right.$ to $\left.139^{\circ}\right)$ & $<0.05$ \\
\hline PFD straining (mm) & $-9(0$ to -4$)$ & $-6(-13$ to -3$)$ & \\
\hline PFD evacuation (mm) & $-37(-47$ to -23$)$ & $-32(-43$ to -27$)$ & \\
\hline \multicolumn{4}{|l|}{ Radiotelemetry } \\
\hline IRP rest $\left(\mathrm{cmH}_{2} \mathrm{O}\right)$ & $5(5$ to 10$)$ & $10(5$ to 20$)$ & \\
\hline IRP straining $\left(\mathrm{cmH}_{2} \mathrm{O}\right)$ & $30(20$ to 40$)$ & $20(10$ to 40$)$ & \\
\hline IRP evacuation $\left(\mathrm{cmH}_{2} \mathrm{O}\right)$ & $35(15$ to 53$)$ & $40(15$ to 60$)$ & \\
\hline
\end{tabular}

Anal canal pressures at rest (MRP) and on maximal contraction of the anal sphincter during voluntary 'squeeze' (SQP); rectal sensory threshold (SEN), rectal capacity (CAP), and compliance (COM); anismus index (AI), pudendoanal reflex latency (PARL), and external anal sphincter (EAS) electromyographic at rest, on straining, and during evacuation; anorectal angles (ARA) at rest, on percentage of the activity evacuated (\%EVAC), defecation time (DTIME), and rate (DRATE); percentage of the activity evacuated (\%EVAC), defecation time (DTIME), and rate (DRATE);
intrarectal pressures (IRP) at rest, on straining, and during evacuation. (The results are expressed: intrarectal pressures (IRP) at rest,
median, $95 \%$ CIs, and $p$ values).
Figure 1: Anismus index (measured in percentage) recorded in 20 patients, during integrated electromyography of the external anal sphincter, before and after electromyographic biofeedback. (The results were compared with the use of the sign test for paired samples, $p$ value is shown) (range: $30-53$ days). At the end of this period the patient had the anorectal and proctography tests repeated as above.

On subjective assessment after the biofeedback most patients admitted to clinical improvement $(57 \%)$, whereas $29 \%$ were completely asymptomatic, and only $14 \%$ had no appreciable symptomatic change.

The Table gives anorectal monometry, electrophysiology results, and detailed analysis of the results obtained from the isotope proctography tests, performed after the treatment with biofeedback and these are contrasted with those from studies done before biofeedback.

\section{BEFORE BIOFEEDBACK $V$ AFTER BIOFEEDBACK}

\section{Anorectal manometry and electrophysiology}

The anorectal manometry showed no significant change in the intra-anal canal pressures, maximum resting pressure or the increment on voluntary anal sphincter contractions. The proctometrogram, however, showed that the volume of the rectal sensory threshold was reduced $(\mathrm{p}<0.05)$ after the biofeedback, with no

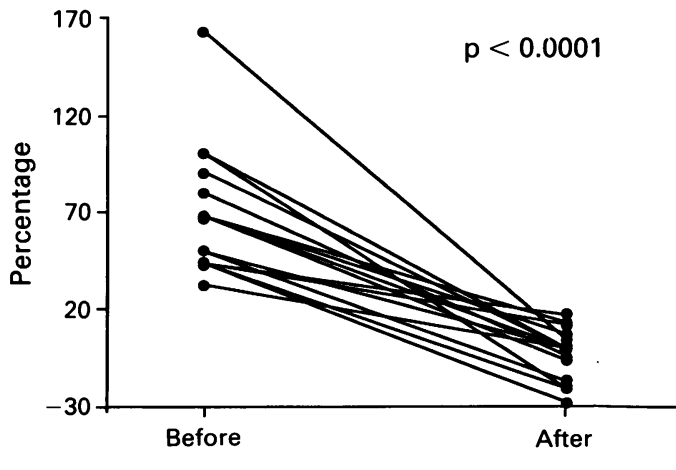

Anismus index noticeable change in the rectal capacity and compliance.

Furthermore, the integrated electromyography recorded via the surface anal plug electromyographic electrode showed a significant reduction in the electromyographic voltage of the external anal sphincter on straining $(p<0.0001)$, with the electromyographic voltage at rest remaining virtually the same. Thus, the anismus index was greatly reduced $(p<0.0001$; Fig 1) after the biofeedback treatment.

\section{Isotope proctography}

The defecation rate, as the relation of the \%EVAC to the defecation time, was significantly increased after the biofeedback ( $p<0.05 ;$ Fig 2$)$. The anorectal angles at rest, on straining, and during evacuation became more obtuse $(\mathrm{p}<0.05$; Fig 3) after the biofeedback. There was a significant increase in the upward ascent movement of the pelvic floor on 'squeezing' $(p<0.03)$, but no difference was seen in the pelvic floor descent.

The \%EVAC during isotope dynamic proctography did not show any significant response to the biofeedback, however, the external anal sphincter electromyographic wire electrode recorded a significant drop in the electromyographic voltage on straining $(p<0.02)$ and on evacuation $(p<0.001)$ whereas the electromyographic voltage at rest was virtually unchanged.

\section{Discussion}

Obstructive defecation is understood to be present in the context of abnormal defecation when there is inappropriate contraction of the puborectalis and external anal sphincter muscles during attempted expulsion, narrowing of the anorectal angle, and an increased pressure in the anal canal retarding defecation. First described by Preston and Lennard-Jones ${ }^{12}$ in female patients with constipation the prevalence of pelvic floor dyssynergia is estimated to occur in almost half of adults with dyschezia and a similar percentage of children with faecal incontinence associated with constipation. ${ }^{13}{ }^{14}$ The underlying aetiopathogenesis of 'spastic pelvic floor' or anismus is uncertain and it has been suggested that laboratory findings may not always resemble the clinical setting. ${ }^{15}$ Nevertheless, if reversal of

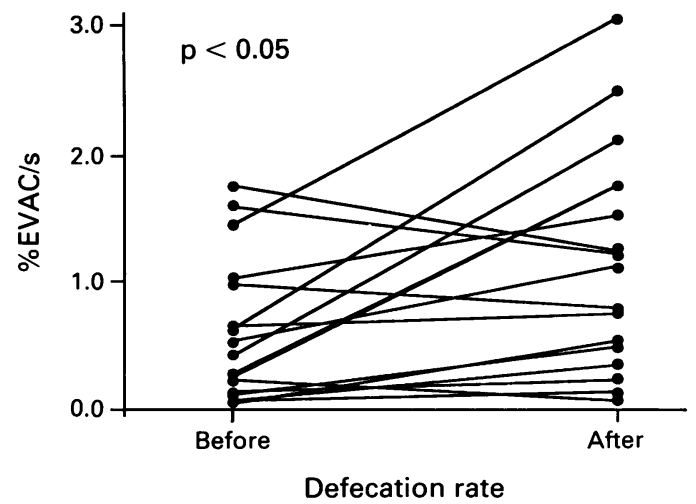

Figure 2: Defecation rate recorded in 19 patients, during isotope proctography, before and after electromyographic biofeedback. (The results were compared with the use of the sign test for paired samples, $p$ value is shown). 


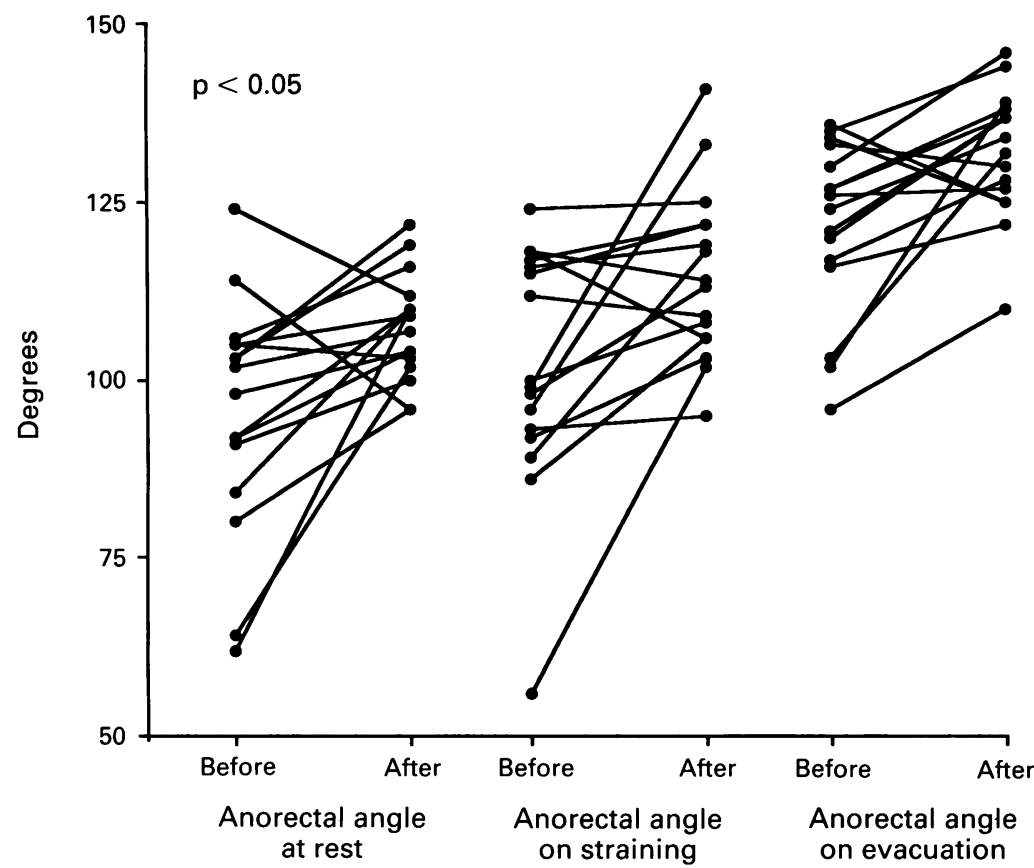

Figure 3: Anorectal angles at rest, on straining, and during evacuation recorded in 19 patients during isotope proctography, before and after electromyographic biofeedback. (The results were compared with the use of the sign test for paired samples, $p$ value is shown). inappropriate activity could be shown to result in clinical improvement, it would support the hypothesis that anismus is a significant cause of chronic constipation.

The study by Kawimbe $e t a l^{8}$ described the use of a portable biofeedback device at home to reinforce initial training. In this study most patients showed symptomatic improvement with effects lasting for at least six months. The comment was made, however, that unless a control (sham treated) group is compared with the biofeedback treated one resolution of symptoms may be attributed to psychological effect of encouragement and positive verbal feedback. ${ }^{15}$ Sham treated biofeedback may not be a successful way of double blind control study because it may not be easy to recruit and randomise constipated anismus patients to achieve objective comparison. ${ }^{16}$ Therefore, an amenable way of assessing a biofeedback effect was to study anorectal parameters including proctographic ones through objective evaluation of biofeedback on anorectal function.

None the less, the psychological influence on patients' anorectal function seems unavoidable during biofeedback training. It must be appreciated, however, that no treatment may be successful unless the patient trusts and believes in it and thus complies. Patients become aware of the fact that they lack relaxation during defecation and focus on it. Relaxed pelvic floor muscles induce more obtuse anorectal angles; thus promoting the passage of rectal contents through the anal canal therefore improving anorectal sensation. An improved sensation may recruit the conscious effort to provoke defecation and, providing the higher centres in control inhibit the contraction of the anal sphincters, rectal evacuation is achieved. Nevertheless, $14 \%$ of patients who do not admit to any clinical improvement had positive objective changes. This may suggest that some of the patients in this group with a long maintained disability may not be so readily influenced by psychological manipulation of their anorectal function.
In this study the patients were investigated before biofeedback, both for elicitation of 'defects' in their defecation mechanisms and for objective changes after biofeedback. The external anal sphincter and the pelvic floor muscles have a continuous level of 'spiking' electrical activity at rest. The external anal sphincter reflex contraction in response to transient rises in intra-abdominal pressure may be seen during the rectosphincter reflex ${ }^{17}$ and proctometrogram. ${ }^{18}$ This is a spinal reflex that seems to be modulated by conscious mechanisms and has its afferent limb in the rectal ampulla. ${ }^{19}$ By steadily increasing the volumes in the rectal balloon the external anal sphincter and puborectalis are inhibited at a certain level. ${ }^{20}$ On defecation, the sphincters relax to permit the passage of the faecel bolus by either the cerebral inhibition of the sphincter contraction or mechanical stimulation, or both in the anal canal. ${ }^{21}$ Once defecation has started, it can continue with no conscious effort, suggesting colonic contraction in response to the faecal bolus passing through the anus. On completion of evacuation the pelvic floor and sphincter muscles regain their previous resting activity and the anal canal closes.

It may be assumed that patients with obstructive defecation have inhibited their defecation reflex at some stage, ${ }^{22}$ presumably because of 'strong' environmental stimuli registering as a life event. As a result the voluntary control of the reflex by higher cortical centres may be lost, which can result in inappropriate use of the pelvic floor and sphincter muscles on attempted defecation, as shown by increased electromyographic voltage of the external anal sphincter activity recorded during proctography. The patients studied had difficulties in starting defecation as well as completing evacuation. This implies a disordered anorectal sensation and stimulation of colonic contraction.

Biofeedback improved the defecation rate by changing the anorectal angles, improving rectal sensation, and diminishing the electromyographic voltage of the external anal sphincter. It has influenced the defecation act at different levels. Therefore, although the act of defecation is a complex phenomenon dependent upon many linked factors in the anorectum and higher centres, it can be influenced by a self regulatory mechanism that depends on the patients' will and effort. ${ }^{10}$

This study presents effects of biofeedback on anorectal function measured objectively for the first time, and shows that biofeedback therefore influenced positively the defecation reflex, ${ }^{23}$ reinforcing its afferent limb by improved anorectal sensation, recruiting the higher centres in the conscious control of the act, and through the efferent limb, provided increased relaxation of the pelvic floor and sphincter musculature.

This work has been supported by a Scottish Home and Health Department Clinical and Biomedical Research Grant (K/MRS/ 5001202). The authors are grateful to Miss Nicola Clare for her technical assistance.

1 Engel BT, Nikoomanesh P, Schuster MM. Operant conditioning of rectosphincteric responses in the treatment of faecal incontinence. N Engl Med 1974: 290: 646-9.

2 Cerulli MA, Nikoomanesh P, Schuster MM. Progress in Biofeedback conditioning for faecal incontinence. Gastroenterology 1979; 76: 742-6. 
3 Constantinides CG, Cywes S. Faecal incontinence: a simple pneumatic device for home biofeedback training. $\mathcal{F}$ Pedtric Surg 1983; 18: 276-7.

4 Schuster MM. Faecal incontinence: biofeedback treatment. In: Henry MM, Swash M, eds. Coloproctology and the pelvic floor - pathophysiology and management. London: Butterworths, 1985: 268-81.

5 Coremans G, Vantrappen G. Faecal incontinence: biofeedback and behavioural treatment. In: Gooszen HG, Ten Cate Hoedemaker HO, Waterman IT, Keighley MRB, eds. Disordered defaecation. Amsterdam: Martinus Nijhoff, 1987: 153-63.

6 Wald A, Hinds JP, Caruana BJ. Psychological and physiological characteristics of patients with severe idiopathic logical characteristics of patients with severe

7 Bleijenberg G, Kuijpers HC. Treatment of the spastic pelvic floor syndrome with biofeedback. Dis Colon Rectum 1987; floor syndrom

8 Kawimbe BM, Papachrysostomou M, Binnie NR, Clare N, Smith AN. Outlet obstruction constipation (anismus) managed by biofeedback. Gut 1991; 32: 1175-9.

9 Anonymous. Anismus and biofeedback [Editorial]. Lancet 1992; 339: 217.

10 Smith L. Biofeedback in anismus: the truth be known? Outlet obstruction constipation managed by biofeedback. Am $\mathcal{F}$ Gastroenterol 1992; 87: 1058.

11 Papachyrsostomou M, Griffin TMJ, Ferrington C, Merrick MV, Smith AN. A method of computerised isotope dynamic proctography. Eur $\mathcal{F}$ Nucl Med 1992; 19: 431-5.

12 proctography. Eur 7 . Nucl JE. Anismus in chronic constipation. Dig Dis Sci 1985; 30: 413-8.

13 Loening-Baucke V. Modulation of abnormal dynamics by biofeedback treatment in chronically constipated children with encopresis. F Pediatr 1990; 116: 214-22.

14 Miller R, Duthie GS, Bartolo DCC, Roe AM, LockeEdmunds J, Mortensen NJMcC. Anismus in patients with normal and slow transit constipation. Br F Surg 1991; 78: 690-2.

15 Merkel IS, Wald A. Training for straining: biofeedback for pelvic floor dyssynergia. Am $\mathcal{f}$ Gastroenterol 1992; 87: $1223-4$

16 Turnbull GK, Ritvo PG. Anal sphincter biofeedback relaxation treatment for women with intractable constipation symptoms. Dis Colon Rectum 1992; 35: 530-6.

17 Arhan P, Devroede G, Danis K, et al. Viscoelastic properties of the rectal wall in Hirschprung's disease. $\mathcal{F}$ Clin Invest 1977; 62: 82-7.

18 Varma JS, Smith AN. Reproducibility of the proctometrogram. Gut 1986; 27: 288-92.

19 Parks AG, Porter NH, Melzak J. Experiemental study of the reflex mechanism controlling the muscles of the pelvic floor. Dis Colon Rectum 1962; 5: 407-4.

20 Kerremans R. Electromyographical activity of the striated circum-anal musculature. In: Kerremans R, eds. Morphological and physiological aspects of anal continence and defecation. Bruxelles. Arscia SA, 1969: 197-228.

21 Duthie HL. Dynamics of the rectum and anus. Clinics in Gastroenterology 1975; 3: 467-77.

22 Kock NG, Kewenter J, Sundin T. Studies on the defaecation reflex in man. Scand f Gastroenterol 1972; 7: 689-93.

23 Papachrysostomou M, Smith AN. Defecation reflex - a biofeedback study. [Abstract]. Proceedings of I United European Gastroenterology week. Athens: September Europed 